\title{
Adaptive Process for SMART Community Governance under Persistent Disruptive Risks
}

\author{
Norio Okada ${ }^{1}$
}

Published online: 12 December 2018

(C) The Author(s) 2018

\begin{abstract}
This article addresses the increasing need for participatory approaches to disaster reduction at the community level. Based on the author's 30-year engagement in the mountainous community Chizu Town, Tottori Prefecture, Japan, a unique participatory approach called "Zeroto-One Movement" has been strategically studied. The study areas are found to have adaptively increased their coping capacity. Their unique participatory process is shown to be an adaptive process for SMART community governance under persistent disruptive risks- "S" represents small-sized and survivability-minded, "M" modestscale and multiple-stakeholder involved, "A" anticipatory and adaptive, " $R$ " risk-concerned and responsive, and " $T$ " is transformative. Finally, the Case Station-Field Campus scheme is proposed to serve as a platform for studying the adaptive processes over a long period of time.
\end{abstract}

Keywords Case Station-Field Campus scheme $\cdot$ Japan $\cdot$ Persistent disruptive risks $\cdot$ SMART governance $\cdot$ Zero-to-One movement

\section{Introduction}

One of the lessons learned after the 1995 Hanshin-Awaji Earthquake disaster in Japan was the need to address citizen-led participatory approaches to disaster risk reduction before disasters, as well as for disaster recovery and

Norio Okada

kyotookanori@gmail.com

1 Institute of Disaster Area Revitalization, Regrowth and Governance, Kwansei Gakuin University, Nishinomiya City 662-0891, Japan revitalization after disasters (Okada 2010, 2016). At the core of the issue is people's increased exposure to disaster risks. To reduce such disaster risks, each community's coping capacity with disasters has to be strategically improved, in parallel with the importance of governments' roles and leadership in disaster risk reduction (Okada 2016).

Since then, the need for participatory approaches to disaster reduction at the community level has been repeatedly confirmed by a series of large-scale, natural hazard-induced disasters that have occurred across Japansuch as the 11 March 2011 Eastern Japan Earthquake disaster, the 14 and 16 April 2016 Kumamoto Earthquake disaster, and most recently the July 2018 Western Japan Heavy Rainfall Disaster, which claimed more than 220 lives and devastated many areas of western Japan (The Asahi Shinbun, 8 July 2018).

To understand the emerging need for such a significant change in disaster planning and management in Japan, one must understand the contrasts between Kyojo (neighborhood or community self-reliance), Jijo (individual or household self-reliance), and Kojo (government assistance). Realizing the limitations in the government's capacity to provide immediate and direct support for relief and recovery after a large-scale disaster, Japan has shifted more towards increasing both the Kyojo and Jijo self-reliance roles, and to depend less on Kojo, which in the past has been the major agent to mitigate disasters. This is a good example of disaster risk governance in public-private-individual partnership. Though some progress has been made to improve community disaster resilience with this approach, it has its own limitations. One problem is how to initiate such a participatory approach and who will be able to facilitate the whole process. Another is how to involve community stakeholders who have not been 
previously engaged in disaster issues. It is a question of engaging a broader range of stakeholders in social processes (Okada 2006a, b; Okada, Fang et al. 2013; Okada, $\mathrm{Na}$ et al. 2013). To address this question properly, we need a much broader scope by not limiting ourselves to disaster concerns, but by also addressing a wide array of day-to-day community concerns.

\section{Addressing the Whole Mix of Community Problems: The Machizukuri Approach in Japan}

Okada, Fang et al. (2013) proposed systematic conceptual models for understanding the machizukuri (bottom-up citizen-led participatory approach) in Japan. ${ }^{1}$ Figure 1 illustrates the multilayer common spaces (an extension of the concept of infrastructure) for a city, region, or neighborhood community as a living body (Okada 2006b). In the context of this pagoda model, machizukuri is more appropriately applied at a neighborhood community scale, rather than at a wider scale, such as city or region. Applied to a neighborhood community in the context of a five-storied pagoda model, it starts with the fifth layer (daily life), followed by the fourth (land use and built environment), and the third (infrastructure). By comparison, toshikeikaku (urban planning) focuses mainly on the fourth and third layers. Another point of contrast is that machizukuri requires citizen involvement to induce attitudinal or behavioral change, while this issue is not essential for toshikeikaku. This kind of machizukuri process is a human-centered approach, and has its basis in the fifth layer-people's lives. It is commonly initiated by people at the top and then proceeds to the lower layers, and back and forth. The machizukuri process is the opposite of the traditional type of urban planning headed by experts and administrative bodies. By convention we call the latter a topdown approach and the former a bottom-up approach, but the pagoda model (Fig. 1) challenges this mindset and argues that it could be upside-down, depending on our standpoint.

The dynamic processes of machizukuri in implementing such a change can be explained and systematically modeled by the nested Plan-Do-Check-Action (PDCA) cyclic structure (Okada 2006a, 2011, 2012; Fig. 2). The "plan" segment in each cycle is set as a hypothetically-workable countermeasure for their committed small change. It is designed to evolve step by step, from small through middle to large cycle, thus changing adaptively and spirally. In structure such a PDCA cyclic process is analogous to the methodological approach of adaptive management. As a hypothetical countermeasure the plan characterizes the essential feature of active adaptive management (see Sect. 3.6).

\footnotetext{
${ }^{1}$ For machizukuri see Okada (2016).
}

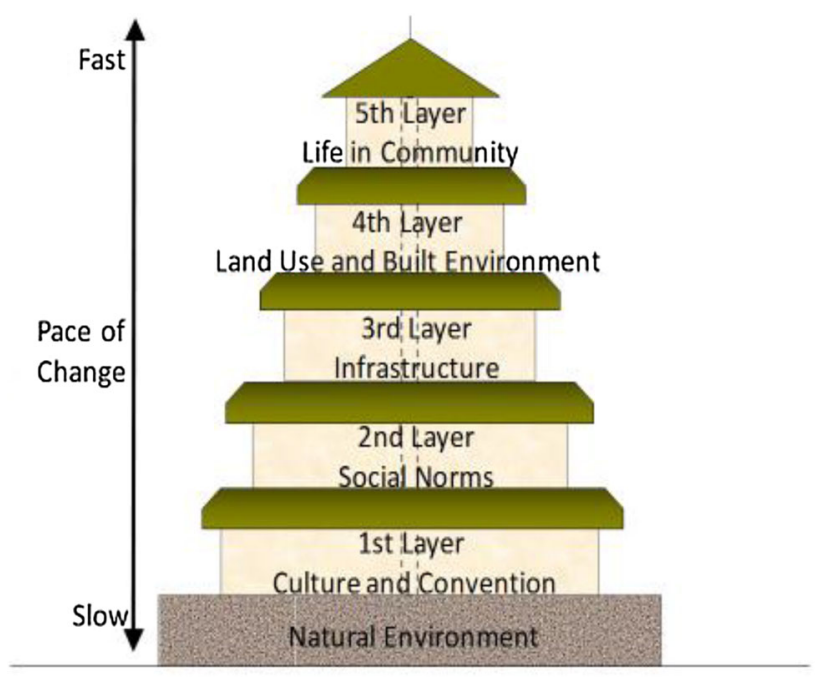

Fig. 1 Five-story pagoda model of the common spaces in a city, region, or neighborhood community

\section{Adaptive Process for SMART Community Governance under Combined Risks of Rural Decline and Disaster Devastation: The Case of Chizu Town, Tottori, Japan}

Figure 3 shows the mountainous location of Chizu Town, Tottori Prefecture, Japan. This town is a typical type of mountainous municipality in the western part of Japan, with a population of 6689 as of October 2018. It is located about $500 \mathrm{~km}$ in direct distance west of Tokyo. The town is a part of Tottori Prefecture (whose capital city is Tottori City), which faces the Sea of Japan. As of 2018, this prefecture has a population of about 570 thousands, and it ranks at the bottom in population among the 47 prefectures in Japan. Chizu Town is a very old community known to exist since the ninth century but especially since the $1950 \mathrm{~s}$ until now, it has been suffering from constant loss of population and rural decline. The major industry has been forestry (timber industry) combined with rice and other agricultural production. A high quality of cedar timber has long been known as a local brand in Japan.

Figure 4 shows that Chizu Town has long been suffering from loss of population, particularly of younger people under 65 , resulting in the gradual increase of the proportion of people over 65. Many other municipalities, particularly in rural areas, have also long been suffering a similar kind of community decline that is commonly called the Kaso (hollowing out) syndrome in Japanese. Governmental efforts have been immense to stop this degradation, by constantly supplying subsidies and making public investments in suffering rural areas, but without much success. People in most rural area communities tend to become less able to cope with their problems by themselves. Chizu Town used to be among them until the early 1980s, but 


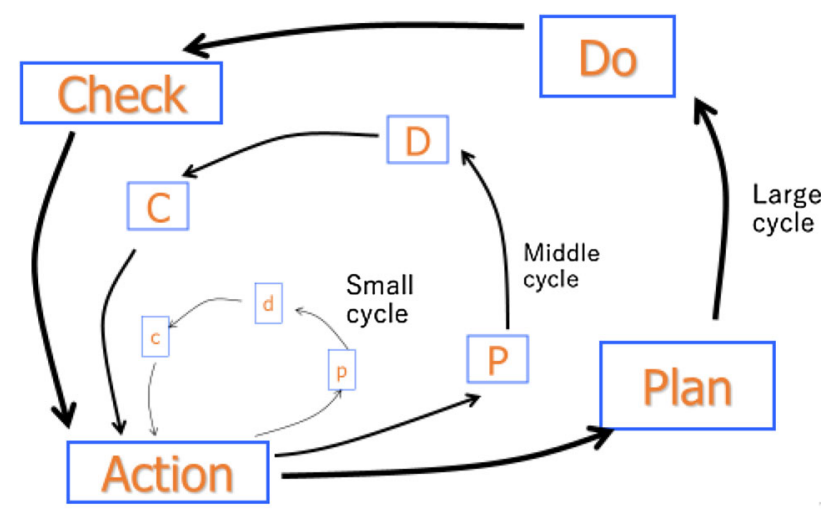

Fig. 2 Nested structure of the Plan-Do-Check-Action (PDCA) process designed to evolve spirally

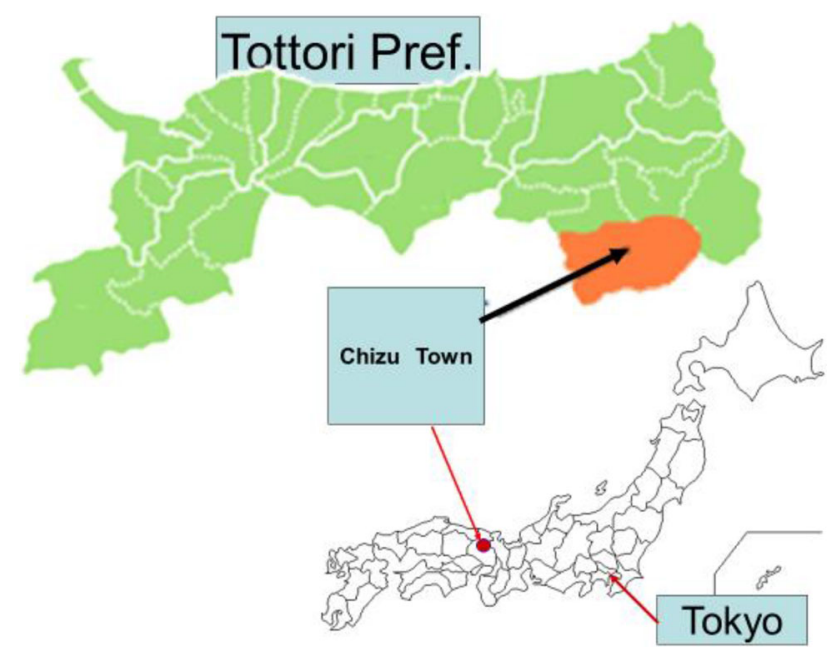

Fig. 3 Location of Chizu Town, Tottori Prefecture, Japan. Source http://www1.town.chizu.tottori.jp/dd.aspx?menuid=1 turned out to be one of the exceptions at about the time the author was invited to the town by a local leader and his local vitalization team in 1985 .

Since then, the author has been conducting communitybased field studies in Chizu, in close collaboration with social scientists led by Sugiman (2001, 2006; see also Okada and Sugiman 1996; Kawahara and Sugiman 2003). The field studies are characterized by transdisciplinary research challenges, and strategically designed to be a three decade-long evidence-based investigation and systematic documentation of the three decade-long process of machizukuri, a unique resident-led participatory approach characterized by the revitalization challenges of their local communities and a step-by-step transformation of their social systems.

\subsection{Three Decades of Zero-to-One Machizukuri Transformation Processes in Chizu}

Decade I: 1987-1997. Local leader-led challenge to make a small initial change (improvement)-learning stage;

Decade II: 1997-2007. Zero-to-One Project (Stage 1) designed and implemented for motivated village communities-first proposal and implementation;

Decade III: 2007-2017. Zero-to-One Upscaled Project (Stage 2) designed and implemented for motivated valley-wide village communities - second proposal and implementation;

Decade IV: 2018 onwards. Project yet to be selfdeveloped by community people.
Fig. 4 Population change in Chizu Town, Tottori Prefecture, Japan, 2005-2020. Source http://www1.town.chizu.tottori. jp/dd.aspx?menuid=1

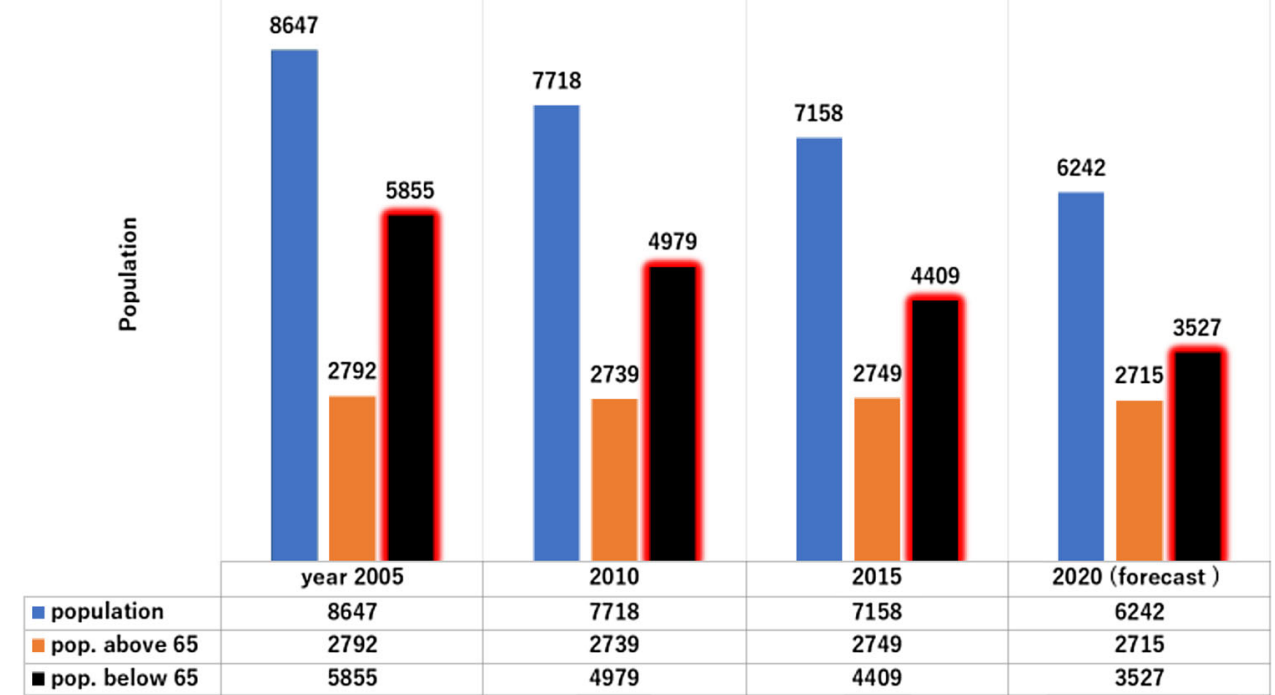


Fig. 5 Conventional top-down rescuing approach by the government like a lifting crane (left) versus the bottom-up approach by the Zero-to-One scheme like a rising balloon (right)

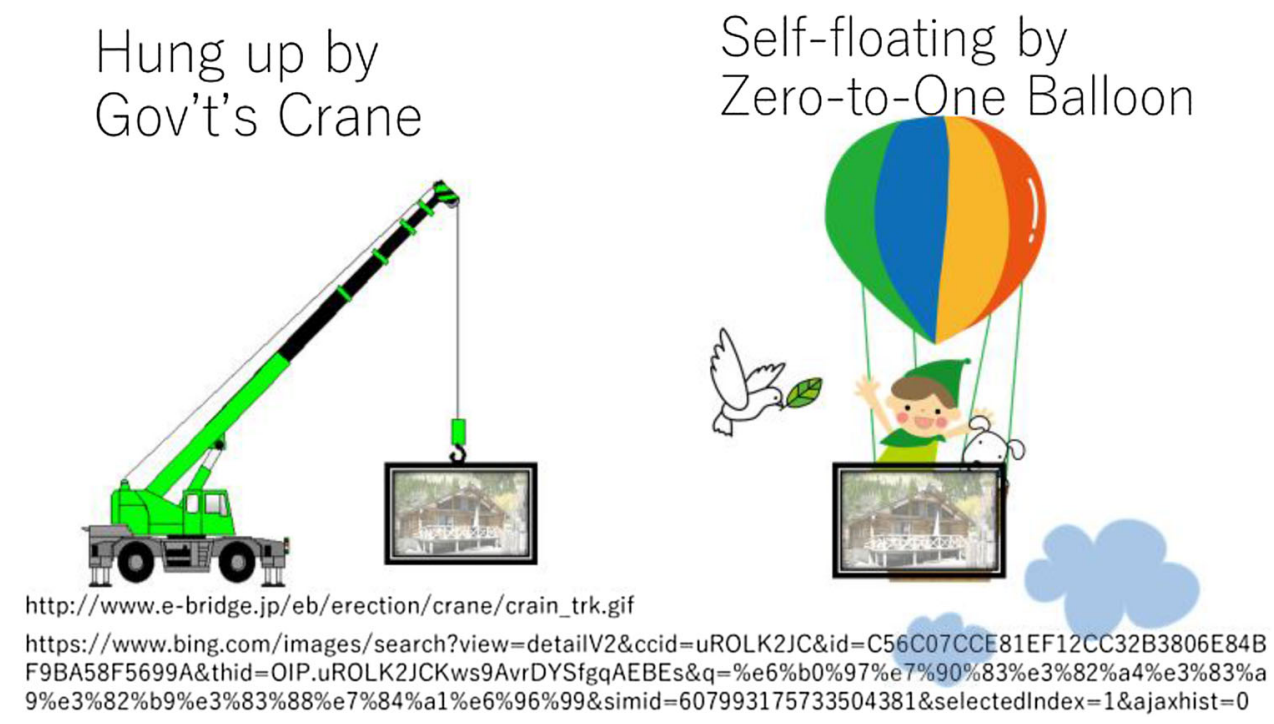

https://www.bing.com/images/search?view=detailV2\&ccid=uROLK2JC\&id=C56C07CCE81EF12CC32B3806E84B $9 \%$ e3\%82\%b9\%e3\%83\%88\%e $7 \% 84 \%$ a1\%e6\%96\%99\&simid $=607993175733504381$ \&selectedlndex $=1 \&$ ajaxhist $=0$

\subsection{What is the Zero-to-One Community Vitalization Movement?}

This movement has two aspects: (1) design of a SMART governance scheme for communities motivated to pursue transformation and willing to experiment with ways to change; and (2) within this framework, each participating community accepts the challenge to become engaged in their own vitalization project by proposing and implementing small-scale, self-governance actions. SMART is an acronym: "S" represents small-sized and survivabilityminded, " $\mathrm{M}$ " modest-scale and multiple-stakeholder involved, "A" anticipatory and adaptive, "R" risk-concerned and responsive, and " $\mathrm{T}$ " transformative. ${ }^{2}$

The name and concept of the Zero-to-One Movement was originally proposed by the author and then adopted by the Chizu Creative Project Team (CCPT), a resident-led voluntary group. Zero-to-One Movement indicates that the movement is anchored to and starts from an extremely small, easily understandable and manageable step that leads gradually to a change-making practice that can recover and revitalize a community's identity (thus getting to "one"). This is an essential process of machizukuri, particularly in rural communities that have been stressed by loss of population and a decrease in coping capacity. In 1996, the scheme was proposed to the then Mayor of the town by the CCPT and finally approved by the local council.

\footnotetext{
2 SMART governance is differentiated from "smart" in the sense of smart technology or smart grid design.
}

\subsection{The Three Pillars of the Zero-to-One Movement}

The Zero-to-One self-governance project requested participating communities to adopt and comply with the following three principles to win back the community's selfgovernance capacity:

(1) Make intracommunity communications more open and promote communication with outside communities;

(2) Reestablish local pride and autonomy; and

(3) Undertake community resource development and management.

Participating communities are qualified to join the project only if they have successfully set up their own project promotion associations (Zero-to-One Community PPA) within their communities. The level of this qualification condition was set higher for the Zero-to-One Upscaled Project (Stage 2), because all communities located in the same valley had to agree to form a joint project promotion association. At the initiation of Stage 2, the participating communities in the same valley (called district) had already set up their self-governance body, Zero-to-One District Community PPA. Importantly, with such PPAs, people now have an institutional platform to become engaged in the small-change (transformation) project (for this Zero-toOne Movement approach see also Sugiman 2006).

\subsection{Major Outcomes and Findings}

Administrators, academics, other experts, and local residents attended an annual evaluation meeting. As of the end 


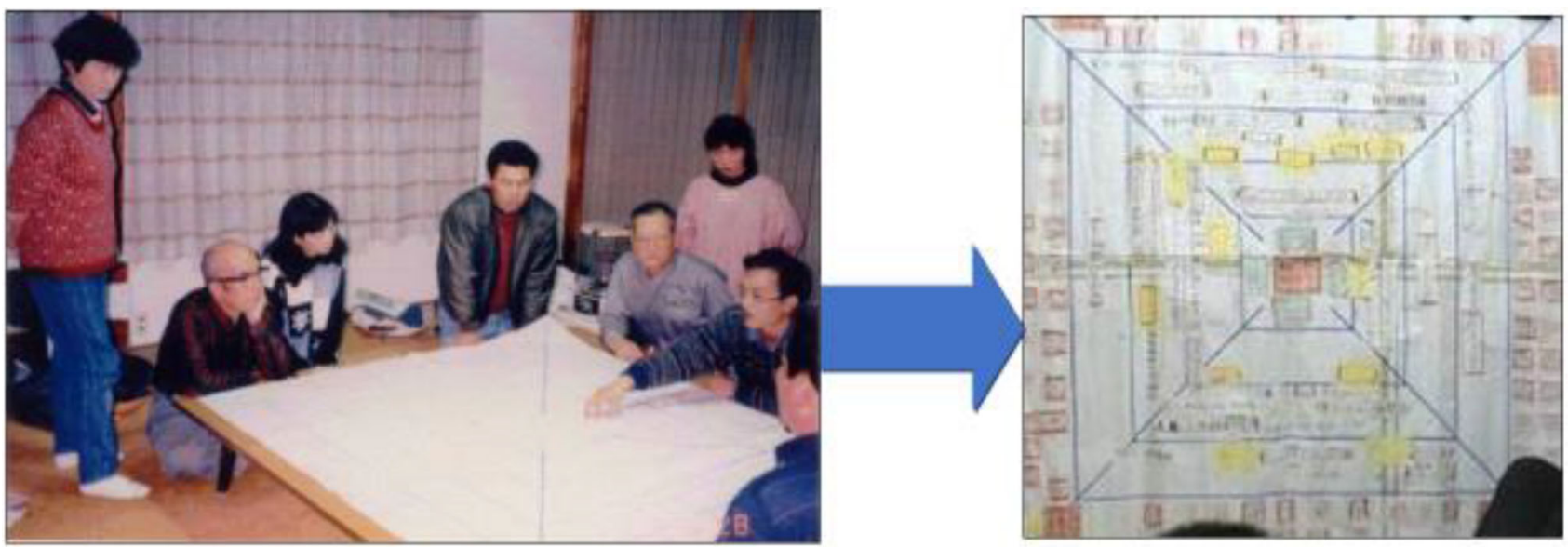

The Yonmenkaigi system (YSM), originally designed and used for collaborative action development for small groups in community-citizen vitalization initiatives (Machizukuri) in a mountainous area of Chizu Town, Tottori, Japan
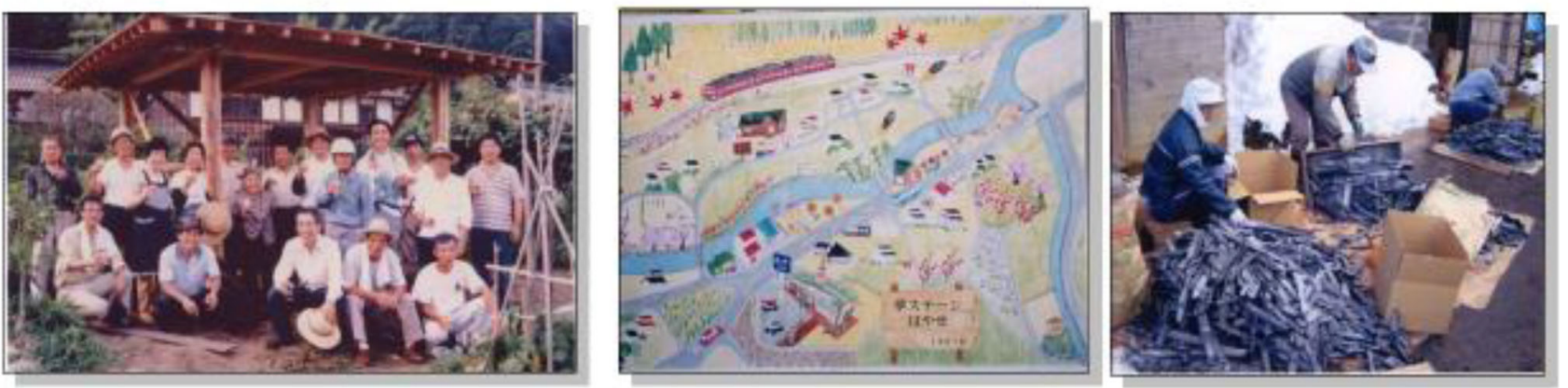

Fig. 6 Chizu Town's challenges to build a common platform with the use of the Yonmenkaigi System Method (YSM)—Hayase village community, Zero-to-One Stage 1. (The upper-left photo shows the scene of community people participating in a workshop by use of the Yonmenkaigi System Method (YSM). The YSM chart-based community plan developed by the people is shown in the upper-right photo. After building up together a small community rest area, the community people posed for the lower-left photo. The lower-middle photo shows the community vision painted and developed together by the village people of Hayase, Chizu Town. In the lower-right photo people were working together to pack up their local product according to their community plan. Photos: Courtesy of Mr. Shoichiro Nagaishi (upper left, taken in December 1996), Mr. Jon-il Na (upper right, November 2006), Mr. Shoichiro Nagaishi (lower left, June 1997), Mr. Jon-il Na (lower middle, November 2006), and Mr. Shoichiro Nagaishi (lower right, November 2006)) of 2017, major visible outcomes included: the reestablishment of a self-governance body at the valley level and the successful reuse of abandoned elementary schools for the purpose of a local-cuisine ecorestaurant, office spaces for small industries, and a local pension business startup for community residents, among others. New lifestyles have also been introduced in the town, such as new residents starting a Waldkindergarten (German for kindergarten in the forest) in Chizu Town, running an ecofriendly bakery and a brewery using fermentation with wild yeast, and a restaurant in a renovated former kindergarten.

Figure 5 compares the conventional top-down approach (left) and the Zero-to-One Movement project bottom-up approach (right). The conventional top-down approach repeatedly rescues local communities suffering from ruraldecline stressors (due to loss, an aging population, and other macrosocial phenomena), diminishing the coping capacity of communities, worsened by the loss of pride and hope in living in their communities. In contrast, the Zeroto-One machizukuri scheme is designed to provide the special leverage needed for a small transformation to be adaptively promoted by the respective communities themselves.

Another significant outcome of the three decade-long machizukuri practices in Chizu is the scientific observation and evidence-based field research conducted by researchers and students. These research-education combined activities were smoothly performed on the basis of the common platform that has been gradually built up in the process of social implementation.

Figure 6 illustrates an example from Hayase village community where the Zero-to-One common platform was 
Fig. 7 The Case Station-Field Campus (unit) scheme to support collaborative research

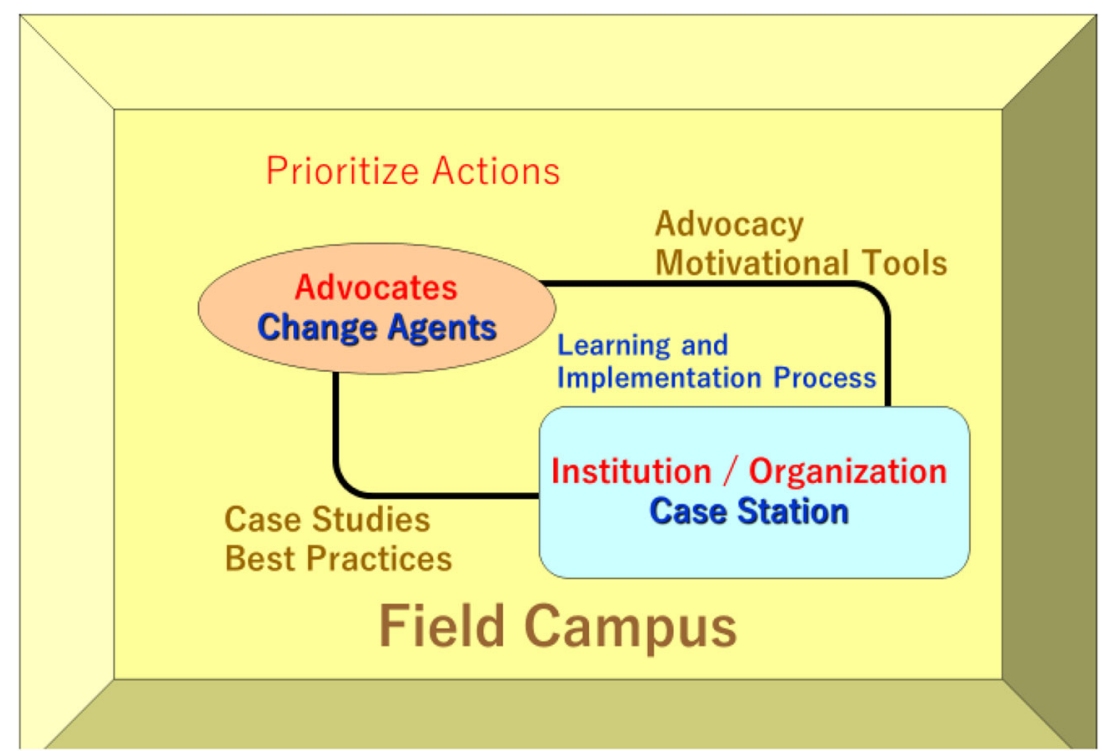

effectively created by using the Yonmenkaigi System Method (YSM), a unique workshop method originally developed in Chizu by Okada and others (Okada, Fang et al. 2013; Okada, $\mathrm{Na}$ et al. 2013). In this case, the stakeholders included the local leader, local elderly residents (traditionally mostly males but in this project also females), local non-elderly residents including females and children, and local government officials (as advisers), together with researchers (as observers and advisers) and students (assistants). In other Zero-to-One project communities, similar common platforms have been strategically activated by use of the YSM, which has been commonly implemented in multiple project areas as a testable model.

\subsection{People's Coping Capacity Challenged by the Western Japan July 2018 Heavy Rainfall}

During the latest Western Japan Heavy Rainfall Disaster (The Asahi-Shinbun, 8 July 2018), Chizu Town also suffered an extraordinarily heavy rainfall disaster over 3 days, with more than $500 \mathrm{~mm}$ rainfall. This was an extreme torrential rainfall on an unprecedented scale, even exceeding the previously worst-case scenario of the 1961 Muroto Typhoon Disaster.

A quick field survey by the author showed that there was no loss of life in any of the villages that have been adaptively transforming their communities to more self-governable ones under different natural and social stressors. People seem to have evacuated in a timely fashion or at least decided to be on alert to evacuate together. In some communities, people made the decision to go to their nearby disaster evacuation shelters instead of running to a more distant public evacuation shelter designated by the town. The Mayor of Chizu took a strong initiative by loudly shouting into a microphone and directing people to be aware that the situation was just unbelievably dangerous and people could lose their lives if they did not evacuate voluntarily. Here are some quotes (or paraphrased comments) from the local people interviewed by the author.

Regarding evacuations:

As we found it wouldn't be safe to run to the public shelter, we decided to evacuate together to our nearest community center. It was a good choice because the designated public shelter was rather distant and we were not sure what would happen on our way.

In our community the situation was worse. Someone reported to us the road to the public shelter was already flooded. This news was immediately shared by everyone in the community and thus we made a choice to go together to our community center for evacuation.

We knew some elderly people in our neighborhood live just by themselves, so we ran to them and helped them to move to the shelter well in advance. Then some younger people stayed in our home, just ready to evacuate.

Some of us took good initiative to judge where to go and guide people.

Regarding the Chizu Town Mayor's "Evacuate immediately message": 
Every one of us immediately recognized his voice and the tone was very special indicating the situation is just extraordinary.

Maybe that was the strongest sense of crisis the Mayor conveyed to us timely and effectively!

People say he is a very good communicator.

Regarding the Zero-to-One Movement:

Without the Zero-to-One movement, we could have coped with this abnormal situation much less effectively and timely.

The Zero-to-One Project Promotion Association (PPA) certainly gives us a better way to work together for a small change, step by step, and issue by issue. Likewise, to prepare for and fight with disaster PPA works a lot.

Our past accumulated experiences through these movements must have helped us increase our coping capacity as a whole.

On the whole, people's coping capacity has been found to work relatively well in the event of a large-scale disaster. A community's coping capacity can be adaptively developed through a variety of ways of handling day-to-day small issues, as well as through learning to fight in the face of natural hazard-induced disasters and social decline issues. As agreed by the village people interviewed by the author and as reflected by the above quotes from the people who experienced the latest heavy rainfall, without their Zero-to-One Movement achievements, the result could have been much worse.

\subsection{Modeling the Zero-to-One Movement Process as an Adaptive Process for SMART Governance}

Okada (2017) proposed to model the dynamic process of the Zero-to-One Movement as an adaptive process for SMART governance. This notion of an adaptive process for SMART governance was developed by the author based on the methodological approach called (active) adaptive management (Holling 1978; Folke et al. 2012). SMART governance refers to the following characteristics and conditions: small-sized and survivability-minded; modestscale and multiple-stakeholder involved; anticipatory and adaptive; risk-concerned and responsive; and transformative.

These five features of SMART governance are proposed by the author as essential characteristics of the Zero-to-One Movement. There could be variants of these essential features.

For instance, one might include self-solidification to the sublist of "S"- "Self-solidification" means that community people take the initiative to concentrate on specific plans, themes, or approach in their adaptive process. Or one could add reflective to the sublist of "R." As it stands now, it is largely arguable how rigorously one could define each of the essential features and their characteristics. This is particularly the case for transformative given that the theme itself entails edge-cutting research frontier issues that are challenged by an innovative approach (see IASS 2018; Folke et al. 2012).

Even if we are at a very preliminary stage of research, the preliminary attempt to call it "SMART governance" will help us examine and design the dynamics of the Zeroto-One Movement in a real context. Although we need further work to examine case by case and area by area, the Zero-to-One Movement could serve as a more generalized adaptive governance process for small change.

From the viewpoint of conducting implementation-oriented field research, it is also important to characterize the Zero-to-One Movement as a strategic approach to set up a common participatory platform that remains over a long period of time. This scheme is called "Case Station-Field Campus" (see Sect. 5).

\section{A More Generalized Adaptive Design Framework: SMART Governance to Survive Persistent Disruptive Risks}

Based on the field-based experience and knowledge development in Chizu, Japan, a further challenge is to develop a more generalized adaptive design framework for implementing SMART community governance under combined natural and social risks. This framework is intended to be implemented in different communities of different countries, in order to design and actualize transformation for more sustainable communities.

At stake are innumerable small communities that will have to survive persistent disruptive risks (PDRs), including the external dynamics of demographic trends, megadisasters, and climate change. ${ }^{3}$ As the 2018 Western Japan Heavy Rainfall Disaster shows, natural hazard-induced disasters tend to occur more frequently in a combined manner (such as typhoon, extreme rainfall, landslide,

\footnotetext{
3 The Intergovernmental Panel on Climate Change (IPCC 2012, p. 1) states: "Extreme weather and climate events, interacting with exposed and vulnerable human and natural systems, can lead to disasters. This Special Report explores the challenge of understanding and managing the risks of climate extremes to advance climate change adaptation. Weather- and climate-related disasters have social as well as physical dimensions. As a result, changes in the frequency and severity of the physical events affect disaster risk, but so do the spatially diverse and temporally dynamic patterns of exposure and vulnerability".
} 
and so on) apparently under the influence of climate change.

The term "disruptive" is introduced to indicate some possible (positive or negative) dynamic impact that results in a (small or large) change in quality or structure of the society or organization under that sort of external risk. Therefore "disruptive" is meant to be different from "destructive". Importantly, "disruptive" means not just deconstructive but it implies opening for innovation (Christensen et al. 2015).

Local impacts of globalization and an interconnected world also act as persistent disruptive stressors (PDSs). ${ }^{4}$ The challenge is how communities are to survive. Under PDS, they need a creative process and a common communication ground, whereby they adaptively learn together with respective stakeholders, transforming their lifestyles and social systems step by step, and eventually establishing SMART governance at the local community level.

With this framework in mind, the issue is how to implement SMART governance. First we need to establish research places in fixed locations and conduct research in a transdisciplinary manner. This has to be carried out over a very long period of time, that is, decade-long at a minimum. A unique and creative resident-led local initiative with strategic objectives and joined by researchers and students is called the "Case Station-Field Campus (CASiFiCA)" (Okada and Tatano 2008). Based on this protocol, multiple aspects of knowledge development are systematically pursued. The primary outcome is what we can call an "adaptive process design for sustainable communities."

\footnotetext{
${ }^{4}$ In the author's research work at the Institute for Advanced Sustainability Studies (IASS), the author has proposed to introduce the notion of persistent disruptive stressors (PDS) to mean basically an equivalent of persistent disruptive risks (PDR) as used in this article. From the viewpoint of a particular living community in focus, and from its residents' concerns, as compared to PDR, PDS might work better for them as the latter sounds more straightforward for people to imagine mega-scale dynamics with a huge potential to force them to survive and change. To be more consistent with risk research terminology, however, more appropriate would be PDR that addresses persistently revisiting the external risks to the community at stake. In conducting transdisciplinary research for some governance purpose, different terms and usages in different disciplines are often different in meaning and thus confusing. Experts' language and people's language are also not always mutually comprehensible. In addition, when we take such a challenge as mentioned here, we sometimes need new expressions or concepts, which add to the communication difficulties. The PDR versus PDS arguments thus lead all concerned to face such challenges in a particular context. When we wish to take a further step towards the social implementation of our research, this is exactly what challenges us.
}

\section{Collaborative Research and Education Schemes Based on the Case Station-Field Campus (CASiFiCA) Scheme}

Acknowledging that diverse efforts have been made for disaster reduction, particularly in disaster-prone areas (countries), many professionals have been energetically and devotedly engaged in fieldwork to reduce disaster risks. They also recognize that more community-based, stakeholder-involved approaches are needed. A crucial question is why we cannot conduct fieldwork more creatively. One promising arrangement to enable us to establish a common communication platform is the CASiFiCA scheme, originally proposed by Okada and Tatano (2008). The CASiFiCA scheme is characterized by a set of local research case study stations and field campuses (Fig. 7). Research case study stations (case stations, for short) are sites at which continuous case studies are conducted strategically by researchers and students stationed in the real field(s). In such real fields local stakeholders are engaged in cases to make a modest change towards betterment of their communities, and researchers and students conduct evidence-based studies, as if the fields were like an academic campus where multilateral knowledge of social implementation is scientifically documented and examined. For this reason, it is called a "field campus." A Case Station and Field Campus (CASiFiCA) is set up as a unit of common platform for field-based collaborative research and education. To promote comparative case studies for different fields with testable models and practices, these units are networked together, across communities in the same region or country or further extended to include global communities. They are called the "CASiFiCA Network."

CASiFiCA has proven successful in promoting IDRiM (Integrated Disaster Risk Management Society) research and education activities. For example, Kumamoto University has successfully taken the initiative to develop a unique multiple-university collaboration disaster education program based on this CASiFiCA scheme (Okada 2018). The initiative also resulted in a new research-education human network, as well as a disaster relief and support communication platform by involving local administrators, the local Red Cross, the local meteorological observatory, local media, and other nongovernmental organizations. The April 2016 Kumamoto Earthquake actually challenged this platform, which was at an early stage of development. Although it was not yet operating at full scale, there was visible evidence of relief support initiatives that were selforganized in a timely manner by students and researchers from the network. Kumamoto University did not lose time to set up a field campus-research laboratory as an outreach 
to the devastated town of Mashiki, south of Kumamoto City.

The University's disaster reduction-related institute has expanded at the entire university level, now covering water, environment, and disaster reduction in a more integrated manner. The Kumamoto-based Case StationField Campus activities are expected to enhance their efforts to connect with other regions, including the Chizu Case Station-Field Campus activities.

\section{Conclusion}

This article addresses the increasing need for a participatory approach for disaster reduction at the community level. Based on the author's 30-year engagement in the mountainous community of Chizu Town, Tottori Prefecture, Japan, a unique participatory approach called "Zeroto-One Movement" has been strategically studied. The study areas are found to increase adaptively their coping capacity. This unique participatory process has been shown as an adaptive process for SMART community governance under persistent disruptive risks. The Case Station-Field Campus scheme has also been proposed to serve as a common platform for studying adaptive design processes over a long period of time.

The Institute for Advanced Sustainability Studies (IASS) has been operating the KLASICA project, headed by Chabay (2017), as an international research alliance. Although KLASICA and CASiFiCA have been developed quite independently from each other, both are aimed at understanding and supporting the development of behavior and attitude change through community processes. A distinct value of KLASICA is its specific concerns with implementation processes and its methodological focus on narratives and affective expressions as an approach to understanding behavior change in communities.

With regard to a reflection of special experience and knowledge and more common experience and knowledge, there remains much room for both approaches to be crossexamined and, if appropriate, synergetic coordination of the two approaches should be considered in the near future. The proposed model of SMART governance to survive under PDR (or PDS) is expected to provide an effective framework for the Case Station-Field Campus (CASiFiCA) scheme. By networking CASiFiCA for different case areas, strategic comparative studies should be conducted in a transdisciplinary manner.

Acknowledgements The author wishes to thank Profs. Ortwin Renn and Ilan Chabay for their valuable comments and advice.

Open Access This article is distributed under the terms of the Creative Commons Attribution 4.0 International License (http:// creativecommons.org/licenses/by/4.0/), which permits unrestricted use, distribution, and reproduction in any medium, provided you give appropriate credit to the original author(s) and the source, provide a link to the Creative Commons license, and indicate if changes were made.

\section{References}

Chabay I. 2017. Overview of KLASICA: An IASS international research alliance. Presentation at the IASS-IDRiM Workshop on Risk Governance for Natural Disasters-Extending Integrated Disaster Risk Management to Sustainable Communities, 29 August 2017, Institute for Advanced Sustainability Studies (IASS), Potsdam, Germany. https://www.iass-potsdam.de/en/ research/knowledge-learning-and-societal-change-alliance-kla sica. Accessed 4 Sep 2018.

Christensen, C.M., Raynor, M.E., McDonald, R. 2015. What is disruptive innovation? Harvard Business Review, December 2015 Issue. https://hbr.org/2015/12/what-is-disruptive-innova tion. Accessed 17 Nov 2018.

Folke, C., Carpenter, S., Elmqvist, T., Gunderson, L., Holling, C.S., Walker, B., Bengtsson, J., Berkes, F., et al. 2012. Resilience and sustainable development: Building adaptive capacity in a world of transformations. Stockholm, Sweden: Environmental Advisory Council, Ministry of the Environment. http://era-mx.org/ biblio/resilience-sd.pdf. Accessed 17 Nov 2018.

Holling, C.S. (ed.). 1978. Adaptive environmental assessment and management. Chichester: Wiley.

IASS (Institute for Advanced Sustainability Studies). 2018. Website. https://www.cigionline.org/partner/institute-advanced-sustain ability-studies-iass. Accessed 22 Nov 2018.

IPCC (Intergovernmental Panel on Climate Change). 2012. Managing the risks of extreme events and disasters to advance climate change adaptation-Special report of IPCC. https://www.ipcc. ch/pdf/special-reports/srex/SREX_Full_Report.pdf. Accessed 17 Nov 2018.

Kawahara, T., and Sugiman, T. 2003. Revitalization of a rural depopulated community by introducing participatory democracy system into each smallest unit of community. The Japanese Journal of Experimental Social Psychology 42(2): 101-119.

Okada, N. 2006a. Perspective on integrated disaster risk management. In Introduction to integrated disaster risk management, ed. Y. Hagihara, N. Okada, and H. Tatano, 9-54. Kyoto: Kyoto University Academic Press (in Japanese).

Okada, N. 2006b. Urban diagnosis and integrated disaster risk management. Journal of Natural Disaster Science 26(2): 49-54.

Okada, N. 2010. City and region viewed as Vitae system for integrated disaster risk management. Annuals of Disaster Prevention Research Institute, Kyoto University, 49B: 131-136.

Okada, N. 2011. A scientific challenge for society under sustainability risks by addressing coping capacity, collective knowledge and action to change: A Vitae System perspective. Journal of Natural Disaster Science 32(2): 53-62.

Okada, N. 2012. Lessons learned from recent disasters in Japan, and implications for ASEAN countries. Keynote presentation at the ASEAN-Japan meeting, 26 June 2012, Naha, Japan.

Okada, N. 2016. Who and how triggers and drives resident-led participatory planning and management for better living environment-Japan's "Machizukuri" challenges. In Indian urbanisation and sustainable development: Spatial perspectives, ed. B.A. Misra, B.N. Singh, H.B. Singh, and K. Lata. Delhi: Kanishka Publishers: 101-115.

Okada, N. 2017. Beyond disaster risk reduction: Smart governance to survive Persistent Disruptive Stressors (PDS). Final Seminar at 
the Institute for Advanced Sustainability Studies (IASS), 16 January 2017, Potsdam, Germany.

Okada, N. 2018. Research networking by Field-Campus and CaseStations (CASiFiCA) for "Build Back Better." In Presentation at the Asian Science and Technology Conference for Disaster Risk Reduction, 17-18 April 2018, Beijing, China.

Okada, N., and Sugiman, T. 1996. A research perspective of rural declining towards the development of community planning research. Journal of Japan Society of Civil Engineers 562(IV35): 15-25 (in Japanese).

Okada, N., and Tatano, H. 2008. Case Station-Field Campus (CASiFiCA): Globally-networked, field-based research and education challenges for disaster reduction. Presentation at the International Disaster and Risk (IDRC) DAVOS Conference 2008, 25-29 August, Davos, Switzerland. https://idrc.info/ fileadmin/user_upload/idrc/former_conferences/idrc2008/presen tations/Program_forWebsite_V7.pdf\#search = 'Davos+conferen ce + Case + StationField + Campus $+\% 28 \mathrm{CASiFiCA} \% 29+\%$
$3 \mathrm{~A}+$ Globallynetworked $\% 2 \mathrm{C}+$ Fieldbased + Research + and + Edu cation+Challenges + for + Disaster+Reduction. Accessed $20 \mathrm{Jul}$ 2018.

Okada, N., L. Fang, and M. Kilgour. 2013. Community-based decision making in Japan. Group Decision and Negotiation 22(1): 45-52.

Okada, N., J. Na, L. Fang, and A. Teratani. 2013. The Yonmenkaigi System Method: An implementation-oriented group decision support approach. Group Decision and Negotiation 22(1): 53-67.

Sugiman, T. 2001. 17-year history of revitalization movement in Chizu. Proceedings of Kasology Trilateral 1st Conference in Chizu, Japan, 1-10.

Sugiman, T. 2006. Theory in the context of collaborative inquiry. Theory and Psychology 16(3): 311-325.

The Asahi Shinbun. 2018. Death toll hits 81 as western Japan braces for more heavy rain. 8 July 2018. http://www.asahi.com/ajw/ articles/AJ201807080023.html. Accessed 15 Aug 2018. 